\title{
Unilateral Condylar Hyperplasia: A Thee-Dimensional CBCT Morphometric and Volumetric Evaluation of Mandibular Condyle by Open-Source Softwares
}

\author{
Hiperplasia Condilar Unilateral: Evaluación Morfométrica y Volumétrica en TCHC \\ Tridimensional del Cóndilo Mandibular Mediante Softwares de Código Abierto
}

\begin{abstract}
Adriana A. De Stefano ${ }^{1,4}$;Annalisa Di Chicco² ${ }^{2}$ Impellizzeri Alessandra ${ }^{3}$; Serritella Emanuela $^{4}$; Elisabetta Guercio-Mónaco ${ }^{1,4}$ \& Gabriella Galluccio $^{5}$
\end{abstract}

\begin{abstract}
DE STEFANO, A. A.; DI CHICCO, A.; IMPELLIZZERI, A.; SERRITELLA, E.; GUERCIO-MÓNACO, E. \& GALLUCCIO, G. Unilateral condylar hyperplasia: A three-dimensional CBCTmorphometric and volumetric evaluation of mandibular condyle by open-source softwares. Int. J. Morphol., 39(4):1164-1170, 2021.
\end{abstract}

SUMMARY: Unilateral condylar hyperplasia (UCH) is an alteration of the mandibular condyle growth. The aim of this study was to evaluate condyle volume, surface area, and Morphological Index (MI) differences between the affected condyle and an unaffected one in patients with $\mathrm{UCH}$, evaluated through 3D reconstructions cone beam computed tomography (CBCT) images by two open-source softwares. A retrospective cross-sectional study of 16 patients with a certain $\mathrm{UCH}, 9$ females and 7 males with mean age $25.13 \pm 6.8$ years was made. The image obtained from the CBCT of each condyle were reconstructed using the open-source software 3D SLICER 4.6 ®. The volumetric and area measurements of the 3D reconstruction of the mandibular condyle were made using the open-source software NETFABB basic $5.0 \AA$. The mean condylar volume of the hyperplastic condyles was $2.07 \pm 1.51 \mathrm{~cm}^{3}$ and the non-hyperplastic condyles was $1.16 \pm 0.82 \mathrm{~cm}^{3}(\mathrm{p}<0.05)$. The mean area surface of the hyperplastic condyle was $11.77 \pm 3.71 \mathrm{~cm}^{2}$ and the non-hyperplasic condyle mean was $8.05 \pm 2.17 \mathrm{~cm}^{2}(\mathrm{p}<0.05)$. The mean area surface difference was $3.72 \pm 3.57 \mathrm{~cm} 2(28.0 \%)$. The MI of the hyperplastic condyle was $1.8 \pm 0.3 \mathrm{~mm}$ and the non-affected condyle was $1.3 \pm 0.6 \mathrm{~mm}(\mathrm{p}<0.05)$. The use of open-source software for 3D reconstruction with manual segmentation for evaluation of the volume and the condylar surface is a valid tool available to the clinic in the diagnosis and monitoring of patients with condylar hyperplasia.

KEY WORDS: Mandibular condyle; Facial asymmetry; Condylar hyperplasia; Cone-Beam computed tomography imaging three-dimensional; Software.

\section{INTRODUCTION}

Unilateral condylar hyperplasia (UCH) is a unilateral overgrowth disorder of the mandibular condyle due to the non-neoplastic increase in the number of normal cells, which is accompanied by a progressive development of mandibular or facial asymmetry (Nitzan et al., 2008). It can occur at any age and continue past the growth period (Almeida et al., 2015) and is more common in women (Raijmakers et al., 2012). Facial asymmetry is often the reason that patients seek treatment of the disorder (Verhoeven et al., 2013). In many cases, occlusal discrepancies and temporomandibular joint disorder are concurrent symptoms with facial asymmetry (Almeida et al.). Its etiology and pathogenesis are still unclear (Arora et al., 2019). Correct diagnosis of UCH is essential for the treatment of the condition (Olate et al., 2013). Diagnostic methods such as clinical examination, radiographs, and nuclear imaging can be used (Arora et al.). The clinical examination and the history confirm the presence of a progressive facial asymmetry. After clinical examination, the imaging evaluation is essential. Computed Tomography (CT)/Cone beam computed tomography (CBCT) are used for condyle size and characteristics (Guercio Monaco et al., 2019; De Stefano et al., 2020) and are positive for asymmetry in mandibular ramus height; the single-photon emission

\footnotetext{
${ }^{1}$ Professor. Department of Orthodontics, Faculty of Dentistry, University Central of Venezuela. PhD Candidate. "Sapienza" University of Rome, Italy.

${ }^{2}$ Dentist. Private practice, Italy.

${ }^{3}$ Research. Sapienza" University of Rome, Italy.

${ }^{4} \mathrm{PhD}$ Candidate. "Sapienza" University of Rome, Italy.

${ }^{5}$ Associate Professor, Department of Oral and Maxillofacial Sciences, "Sapienza” University of Rome, Italy. https://orcid.org/0000-0002-6876-8839
} 
DE STEFANO, A. A.; DI CHICCO, A.; IMPELLIZZERI, A.; SERRITELLA, E.; GUERCIO-MÓNACO, E. \& GALLUCCIO, G. Unilateral condylar hyperplasia: A three-dimensional CBCTmorphometric and volumetric evaluation of mandibular condyle by open-source softwares. Int. J. Morphol., 39(4):1164-1170, 2021.

computed tomography (SPECT) shows an increase in the uptake of Technetium-99m-hydroxy diphosphonate on bone scintigraphy (Peck et al., 2014). Patients are considered to have hyperactivity of one condyle if the SPECT show a > $10 \%$ left-to-right difference (Saridin et al., 2011). CBCT offers a real-size dataset based on a single low-radiationdose scan; from this dataset, 3D reconstructions and multiplanar cross-sections of the maxillofacial bony structures can be better analyzed (Xi et al., 2013). Therefore, the combined use of CBCT and SPECT could provide a clearer picture of the patient's condition, particularly in relation to hard tissue (Goulart et al., 2017).

The three-dimensional evaluation of the mandibular condyle through the CBCT images allows the identification of the condylar shape and volume with a higher precision rate of the linear measurements (Tecco et al., 2010; Saccucci et al., 2012). In the UCH, this evaluation is of importance for the diagnosis and follow-up of the case.

The aim of the present study was to evaluate condyle volume, surface area, and Morphological Index differences between the affected condyle and an unaffected one in patients with unilateral condylar hyperplasia, evaluated through 3D reconstructions CBCT images by two opensource softwares.

\section{MATERIAL AND METHOD}

A retrospective cross-sectional study was carried out on CBCT of 16 patients with a certain $\mathrm{UCH}$ diagnosis treated at Department of Oral and Maxillofacial Sciences, "Sapienza" University of Rome ( 9 females and 7 males; mean age 25.13 \pm 6.8 years). The UCH was defined by the following inclusion criteria: a clinical history of progressive mandibular asymmetry with a positive SPECT (activity difference between the left and right TMJ condylar region of $>10 \%$ ). The exclusion criteria were patients with mandibular fracture, maxillofacial deformations, previous dentofacial surgery, and systemic or metabolic bone disease. The CBCTs and the SPECT of the patients included in this study were part of the diagnostic records necessary for diagnosis and treatment planning and all patients and / or their parents signed the informed consent for the use of the information for research; patients were not required to undergo additional radiation to justify the study. The study was conducted according to the Declaration of Helsinki on medical protocol and recommendations for research involving human beings.

The Digital Imagining and Communications in Medicine (DICOM) files obtained from the CBCT were reconstructed using the open-source software 3D SLICER 4.6 ® (http://www.slicer.org) (Fedorov et al., 2012). The volumetric and area measurements of the $3 \mathrm{D}$ reconstruction of the mandibular condyle were made using the open-source software NETFABB basic 5.0 ® (https://netfabbbasic.software.informer.com/5.0/). Reconstruction and measurement of one condyle at a time was performed.

\section{D SLICER 4.6 $®$}

3D SLICER 4.6® is an open-source software that allows three-dimensional visualization and processing of medical images.

The 3-D reconstruction of the condyle requires that it be separated, segmented, in all three planes of space, from all the surrounding anatomical structures, both from soft and hard tissues. To achieve this, once the images are loaded to the software, the first step is to cut through the Region of Interest (ROI) to narrow down the area of work. This process is done in the "Volume Rendering" option from the dropdown menu on the toolbar. On clicking the option, a box opens up that allows the frame to be seen; it allows to delimit the space, modifying the limits in the two-dimensional views (Fig. 1). The upper and lower limits of the condyle were standardized. Segmentation was carried out and controlled on all three sections: axial, coronal, and sagittal. On axial and coronal sections, the upper contour of the condyle was defined as the first radiopaque point displayed. The lateral contours for each section were easily identified on all three sections provided through the clear visualization of the cortical bone. On the coronal sections, the lower limit of the condyle was placed where the sigmoid notch disappears: the surface of the coronal section from this point onwards increases rather than decreases. The head of the condyle is easily identifiable on the axial projections where its section progressively changes from an "ellipsoidal" shape (due to the presence of the anterior ridge on the condylar head) to a more "circular" shape (suggesting that the view was at the level of the condylar neck). Once the condyle has been delimited, the "Crop" option must be activated to eliminate the contiguous anatomical structures (Fig. 2).

The contrast adjustment in one of the most important segmentation steps, since it will define places that may not be visible with the default settings. To do this, it is necessary to enter the "Volumes" tool, from the toolbar or the dropdown menu, and select the "Bone" option. With the "Shift" function, the display contrast can be chosen for the 3D image set at 300 for all the analyzed CBCTs (Fig. 3).

To highlight the condyle, a manual method was chosen using axial sections to delimit the bone contours of 
the condyle. The bone color (beige) was selected and was colored using the "Level tracing effect" function on each axial section. Using "Make model effect," creation of the
3D model of the condyle was possible, free from all the surrounding anatomical structures, which were saved in the STL format.

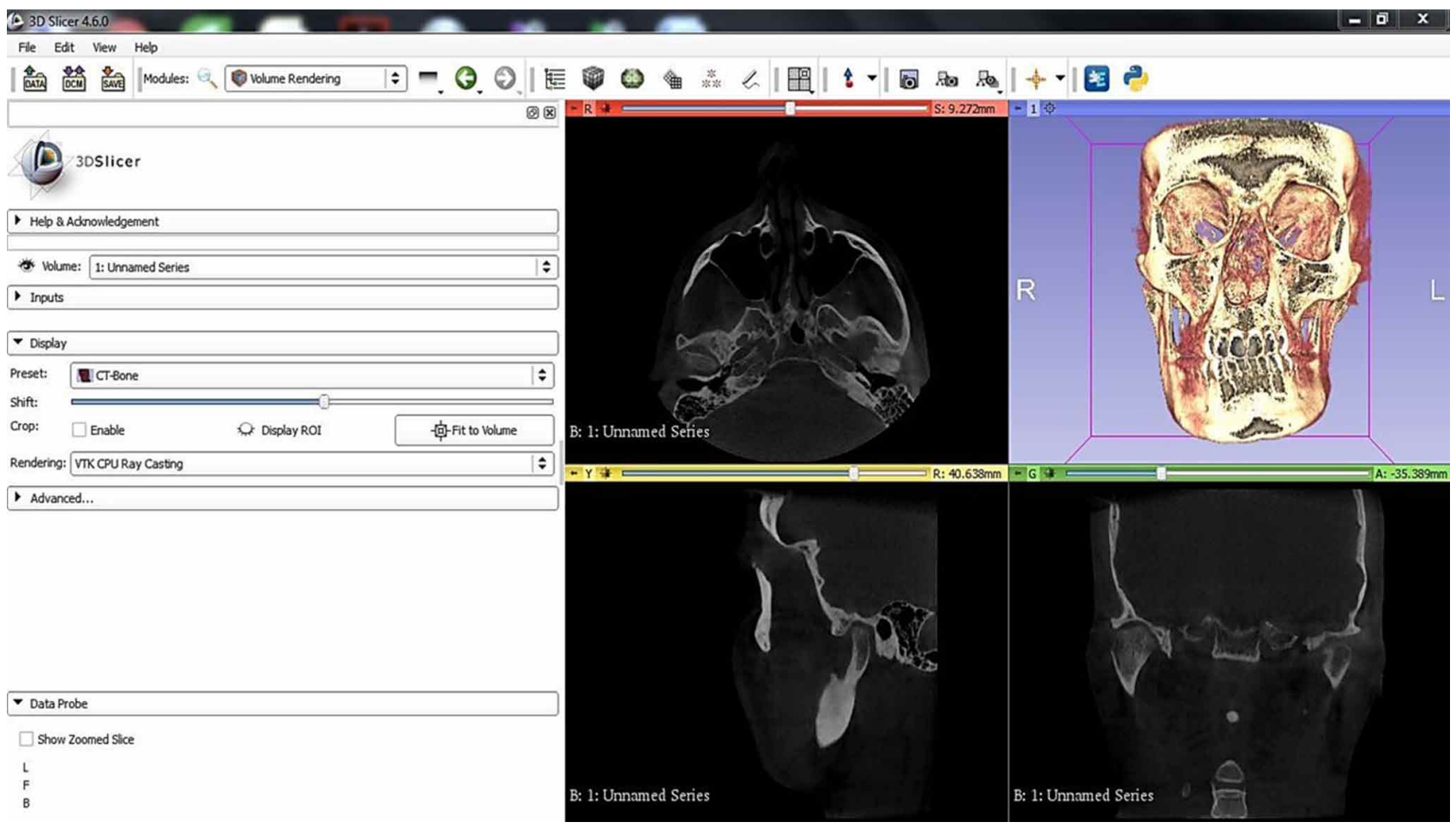

Fig. 1. 3D SLICER 4.6 ®. "Volume Rendering" function.

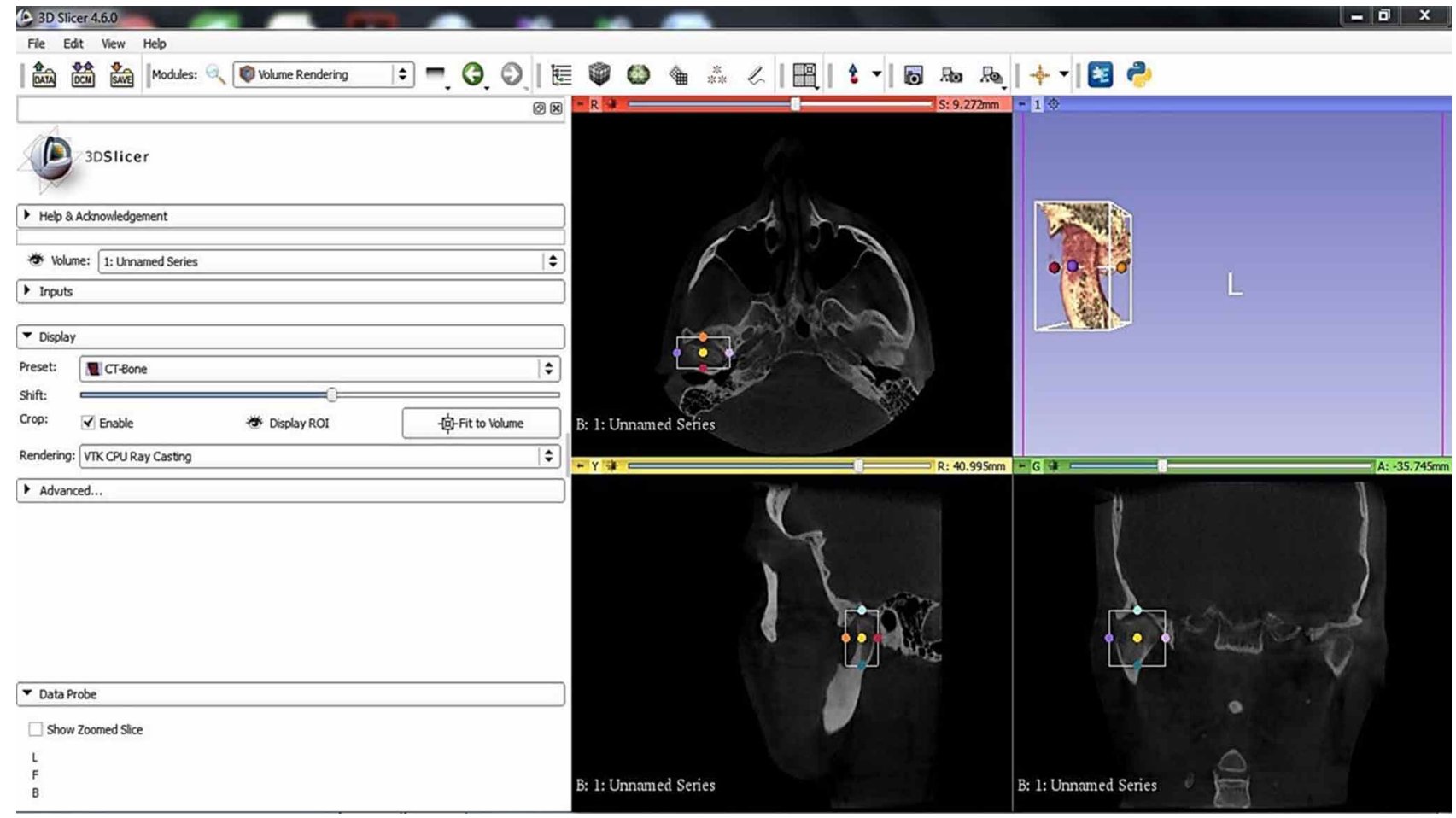

Fig. 2. 3D SLICER 4.6 ®. "Crop" function to cut out the anatomical region of our interest. 
NETFABB basic 5.0 @: This open-source software allows to repair and print 3D models. For the purpose of the study, NETFABB basic 5.0 (B) was used to perform volumetric measurements of the mandibular condyle.

The "Bone" STL file was imported into the NETFABB basic 5.0 ® software and the volume $(\mathrm{cm} 3)$ and surface area $(\mathrm{cm} 2)$ of the mandibular condyles was automatically calculated by the program (Fig. 4).
The researcher evaluated the same images twice with a two-week interval. To determine intra-examiner reliability, Wilcoxon signed-rank test was used. No significant difference was found between the two measurements made by the same operator for volume $(\mathrm{Z}$ $=-0.213 ; p=0.742)$, or for surface $(Z=-0.198 ; p=0.624)$. For this study, the second measures taken were used.

The volume asymmetry index of the condyle (\%)

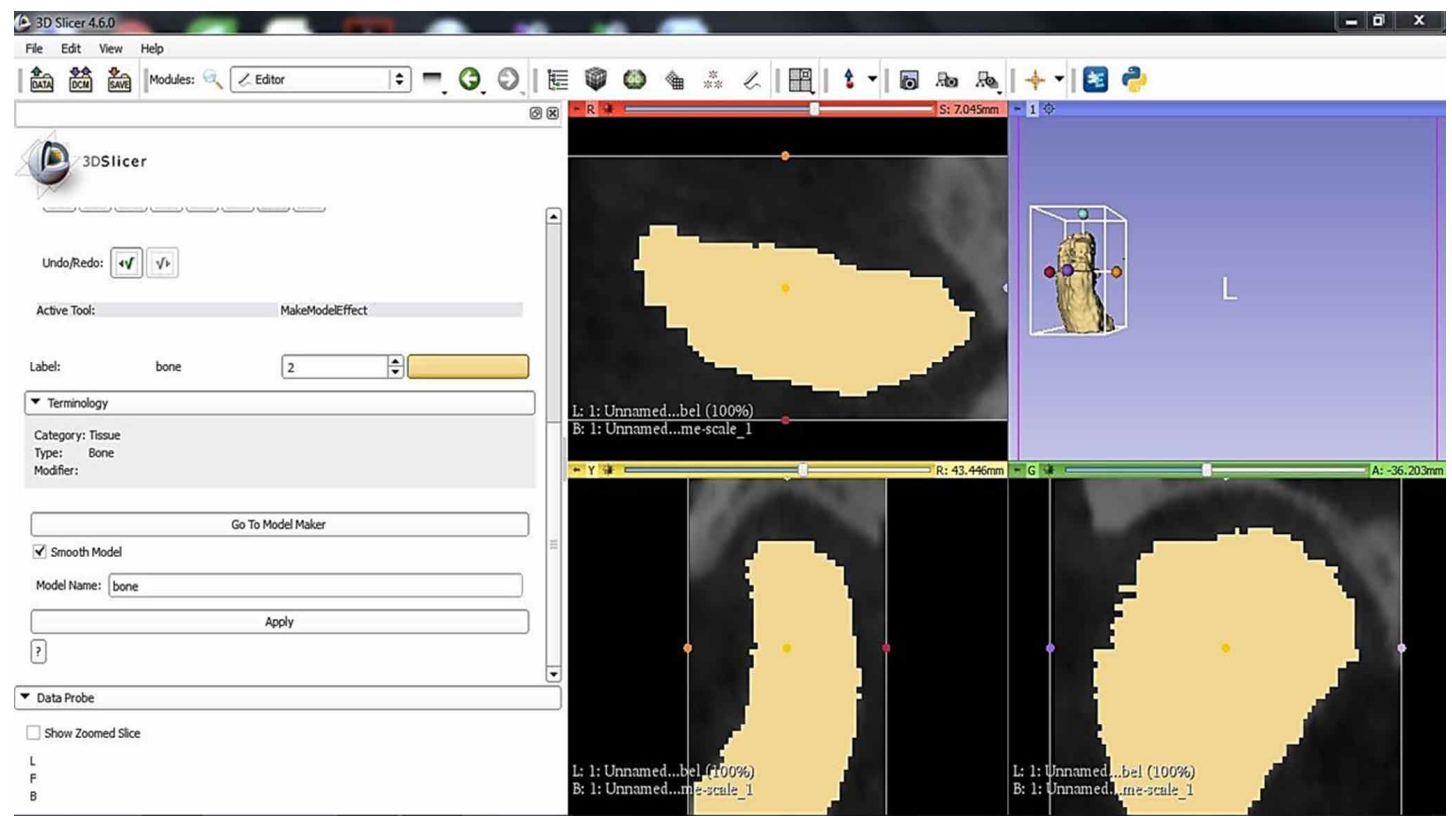

Fig. 3. 3D SLICER 4.6 ®. "Shift" function.

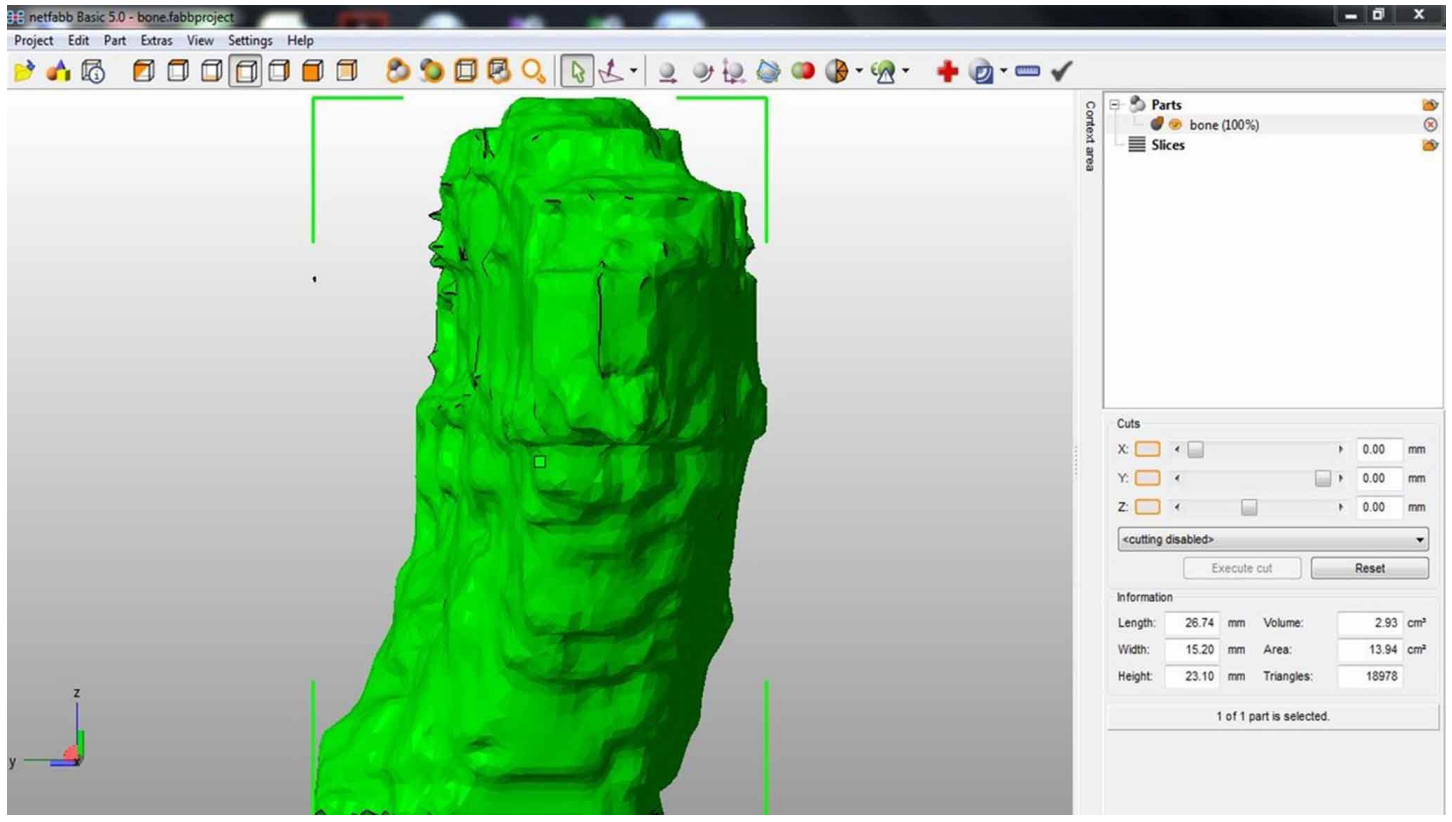

Fig. 4. NETFABB software ${ }^{\circledR}$ Condylar volume and surface area. 
were also calculated, making for each patient the ratio between the difference of the volumes of the two condyles and the sum of the volumes themselves. The result obtained was multiplied by 100 . The surface area asymmetry index was calculated through the same method.

The morphometric index (MI) of hyperplasic condyles and non-affected ones were calculated using the ratio between volume and surface, which allows to evaluate the shape of the examined mandibular condyles.

The measurements were analyzed and processed using the NCSS 11 statistical software. Descriptive statistics were used to define continuous variables (mean, standard deviation, minimum, maximum). Suitability for normal distribution was examined using the Shapiro-Wilk test. The Student's t-test was used to compare the volume and area surface of both hyperplastic and non-hyperplastic condyles. A p-value of $<0.05$ was considered statistically significant.

\section{RESULTS}

The mean condylar volume of the hyperplastic condyles was $2.22 \pm 0.95 \mathrm{~cm}^{3}$ and showed a statistically significant difference with the non-hyperplastic condyles $\left(1.01 \pm 0.54 \mathrm{~cm}^{3}\right)$ $(\mathrm{p}<0.05)$. The mean difference in condylar volume between the hyperplasic condyle and the unaffected condyle was 1.20 $\pm 0.96 \mathrm{~cm}^{3}$. The volume asymmetry index was $27.7 \%$.

The mean area surface of the hyperplastic condyle was $11.77 \pm 3.71 \mathrm{~cm}^{2}$, statistically different from the average area surface of the non-hyperplasic condyle $8.05 \pm 2.17 \mathrm{~cm}^{2}$ ( $\mathrm{p}<$ $0.05)$. The mean area surface difference between the hyperplasic and non- hyperplasic condyle was $3.72 \pm 3.57$ $\mathrm{cm} 2$ and the area surface asymmetry index was $17.7 \%$.

The MI showed significant differences between the hyperplastic condyle $(1,83 \pm 0.3 \mathrm{~mm})$ and non-affected condyle $(1.27 \pm 0.57 \mathrm{~mm})(\mathrm{p}<0.05)$ (Table I).

Table I. Condylar Volume, Condylar Surface Area and Morphometric Index (MI).

\begin{tabular}{lcccccc}
\hline & \multicolumn{2}{c}{ Condylar Volume } & \multicolumn{2}{c}{ Condylar Surf ace Area } & \multicolumn{2}{c}{ Morphometric Index } \\
& $\begin{array}{c}\text { Hyperplasic } \\
\text { condyle }\end{array}$ & $\begin{array}{c}\text { No-Hyperplasic } \\
\text { Condyle }\end{array}$ & $\begin{array}{c}\text { Hyperplasic } \\
\text { condyle }\end{array}$ & $\begin{array}{c}\text { No-Hyperplasic } \\
\text { Condyle }\end{array}$ & $\begin{array}{c}\text { Hyperplasic } \\
\text { condyle }\end{array}$ & $\begin{array}{c}\text { No-Hyperplasic } \\
\text { Condyle }\end{array}$ \\
\hline Mean & 2.22 & 1.01 & 11.77 & 8.05 & 0.18 & 0.13 \\
Standard Deviation & 0.95 & 0.54 & 3.71 & 2.17 & 0.03 & 0.06 \\
Minimum & 1.08 & 0.08 & 6.92 & 5.62 & 0.14 & 0.01 \\
Maximum & 4.24 & 2.04 & 19.52 & 13.89 & 0.25 & 0.18 \\
\hline
\end{tabular}

\section{DISCUSION}

The evaluation of the condylar volume provides important information for the diagnosis and follow-up of patients with mandibular growth disorders (Safi et al., 2018). This evaluation is not possible with conventional radiography, 3D modalities are necessary for quantification of mandibular condyle volumes (Mostafavi et al., 2018) CBCT is increasingly being used as an imaging modality, particularly in the evaluation of TMJ (Bayram et al., 2012).

Various authors have evaluated the condylar volume in healthy patients to obtain a reference value (Alhammadi et al., 2014). Bayram et al., (Bayram et al.) in 2012, determined the accuracy of volumetric analysis of the mandibular condyle using CBCT. Tecco et al. in 2010, evaluated condylar volume and surface in young adult. Saccucci et. al. in 2012, evaluated the condylar volume in Caucasian young adults, comparing with Class I, II, and III and Mostafavi et al., in 2018, compared the size and shape of the condyle in adults with different skeletal patterns. They concluded that the skeletal class appeared to be associated to the mandibular condylar volume and the mandibular condylar area. Nota et al. (2020) detected a significant increase in condylar volume from puberty to young adulthood. Safi et al., in 2018, compared the condylar volume of young and old patients, concluding that significant differences in volumetric measurement of mandibular condyles exist between sex and side, but not in relation to the age and occlusal support.

The condylar volume was also evaluated in patients with UCH. Goulart et al., in 2017, compared the condylar volume between patients with UCH and Class III patients, concluding that hyperplastic condyles were similar in volume to the condyles of patients with mandibular prognathism, suggesting that patients with a Class III skeletal relation could exhibit bilateral condylar hyperplasia. 
Karssemakers et al. (2018) compared the condylar volume and the condylar bone activity, and evaluated with SPECT but did not find any relationship.

It is important in the evaluation of patients with $\mathrm{UCH}$ to have a tool available for the clinician to evaluate condylar volume, which allows to take full advantage of the diagnostic images of the patient by CBCT (Nolte et al., 2016; Safi et al.). That is why some authors have proposed the use of open-source software for the 3D image evaluation. Vellone et al. (2020) compared "gold standard" manual-segmentation with a "semi-manual one', 'using two kinds of open-source softwares to calculate volume of 80 UCH condyles. In this study, manual segmentation was used, as it is considered the reference method, through opensource softwares (Shyu et al., 2015; Wallner et al., 2018; Vellone et al.).

The mean age of the evaluated patients corresponds to the age reported as the most frequent in patients with UHC (between the age of 11-30 years) (Arora et al.) as well as the higher prevalence of the female gender is in agreement with that was reported (Raijmakers et al.).

Significant differences in volumetric and surface measurement of mandibular condyles exist between sex and side, but not in relation to age and occlusal support ( $S$, allı \& Öztürkmen, 2021). The difference between the right side and the left side in healthy subjects is around 4$6 \%$ and can be related to one or more of the following factors: lack of teeth, dental abrasion, presence of precontacts, functional mandibular deviations, posterior unilateral crossbite, and dentoskeletal asymmetries (Tecco et al.; Saccucci et al.).

In this study, it was observed that a significant difference in volumetric and surface area measurement of mandibular condyles between hyperplasic and non-affected condyle with a mean of difference percentage of $27.7 \%$ and $17.7 \%$, respectively. This difference greatly exceeds the suggested cut-off (4-6\%), confirming that this difference is due to the presence of UHC, confirmed with a positive SPECT (Tecco et al.; Bayram et al.).

The mandibular condyle's evaluation through measurements of surface, volume, and MI allows to establish an abnormal shape directly, based on the fact that there is no difference in the MI between the right and left sides and there is no sexual dimorphism. The IM should be between 1.15 and 2.5 in subjects with malocclusion and without symptoms of DTM, and if the values deviate greatly from the range, it could indicate an anomalous shape of the mandibular condyles (Tecco et al.; Saccucci et al.).
In this study, a significant difference was observed between the MI of hyperplasic and non-hyperplastic condyle; however, the values remain in the range of value suggested as normal, indicating that the condylar shape in patients with $\mathrm{UCH}$, despite the increase in volume, remains similar to that of healthy patients.

\section{CONCLUSION}

In the present study, based on patients with unilateral condylar hyperplasia evaluated by CBCT images of threedimensional reconstruction using open-source software, a significant difference in the volume and the condylar surface area was evidenced between the affected and unaffected condyle. However, the MI suggests that the greater volume and surface area of the hyperplastic condyle is threedimensionally uniform, therefore maintaining the shape.

The use of open-source software for 3D reconstruction with manual segmentation for the evaluation of the volume and condylar surface is a valid tool, which is available to the clinician for the diagnosis and monitoring of patients with condylar hyperplasia.

DE STEFANO, A. A.; Di CHICCO, A.; Alessandra, I.; EMANUELA, S.; GUERCIO-MÓNACO, E. \& GALLUCCIO, G. Hiperplasia condilar unilateral: Evaluación morfométrica y volumétrica en TCHC tridimensional del cóndilo mandibular mediante softwares de código abierto. Int. J. Morphol., 39(4):1164-1170, 2021.

RESUMEN: La hiperplasia condilar unilateral (HU) es una alteración del crecimiento del cóndilo mandibular. El objetivo de este estudio fue evaluar en pacientes el volumen del cóndilo, el área de superficie y las diferencias del índice morfológico (IM) entre el cóndilo afectado y el no afectado en pacientes, mediante tomografía computarizada de haz cónico (TCHC), por medio de dos softwares. Se realizó un estudio transversal retrospectivo de 16 pacientes con determinada HU, 9 mujeres y 7 hombres con edad media $25,13 \pm 6,8$ años. La imagen obtenida del TCHC de cada cóndilo se reconstruyó utilizando el software de código abierto 3D SLICER 4.6 ß. Las medidas volumétricas y de área de la reconstrucción 3D del cóndilo mandibular se realizaron utilizando el software de código abierto NETFABB basic 5.0 ®. El volumen condilar medio de los cóndilos hiperplásicos fue de 2,07 $\pm 1,51 \mathrm{~cm}^{3}$ y el de los cóndilos no hiperplásicos fue de $1,16 \pm 0,82 \mathrm{~cm}^{3}(\mathrm{p}<0,05)$. La superficie media del cóndilo hiperplásico fue de $11,77 \pm 3,71 \mathrm{~cm}^{2}$ y la media del cóndilo no hiperplásico fue $8,05 \pm 2,17 \mathrm{~cm}^{2}(\mathrm{p}<0,05)$. La diferencia de superficie de área media fue $3,72 \pm 3,57 \mathrm{~cm}^{2}(28,0 \%)$. El IM del cóndilo hiperplásico fue de 1,8 \pm $0,3 \mathrm{~mm}$ y el cóndilo no afectado fue de $1,3 \pm 0,6 \mathrm{~mm}(\mathrm{p}<0,05)$. Para el clínico, el uso de software de código abierto en la reconstrucción 3D con segmentación manual, para la evaluación del volumen y la superficie condilar, es una herramienta efectiva en el diagnóstico y tratamiento de pacientes con hiperplasia condilar.

PALABRAS CLAVE: Cóndilo mandibular; Asimetría facial; Hiperplasia condilar; Imagen de tomografía computarizada de haz cónico tridimensional; Software. 


\section{REFERENCES}

Alhammadi, M. S.; Shafey, A. S.; Fayed, M. S. \& Mostafa, Y. A. Temporomandibular joint measurements in normal occlusion: A threedimensional cone beam computed tomography analysis. J. World Fed. Orthod., 3 (4):155-62, 2014.

Almeida, L. E; Joseph, Z. \& Pierce, S. Condylar hyperplasia: An updated review of the literature. Korean J. Orthod., 45(6):333-40, 2015.

Arora, K. S.; Bansal, R.; Mohapatra, S. \& Pareek, S. Review and classification update: unilateral condylar hyperplasia. BMJ Case Rep., 12(2):e227569, 2019.

Bayram, M.; Kayipmaz, S.; Sezgin, O. S. \& Küçük, M. Volumetric analysis of the mandibular condyle using cone beam computed tomography. Eur. J. Radiol., 81(8):1812-6, 2012.

De Stefano, A. A.; Guercio-Monaco, E.; Hernández-Andara, A. \& Galluccio, G. Association between temporomandibular joint disc position evaluated by magnetic resonance imaging and mandibular condyle inclination evaluated by computed tomography. J. Oral Rehabil., 47(6):743-9, 2020.

Fedorov, A.; Beichel, R.; Kalpathy-Cramer, J.; Finet, J.; Fillion-Robin, J. C.; Pujol, S.; Bauer, C.; Jennings, D.; Fennessy, F.; Sonka, M.; et al. 3D Slicer as an image computing platform for the Quantitative Imaging Network. Magn. Reson. Imaging, 30 (9):1323-41, 2012.

Goulart, D. R; Muñoz, P.; Cantín López, M. G.; de Moraes, M. \& Olate, S. Comparative evaluation of condylar volume between patients with unilateral condylar hyperplasia and class III dentofacial deformity. J. Oral Maxillofac. Surg., 75(1):180-8, 2017.

Guercio Monaco, E.; De Stefano, A. A.; Hernandez-Andara, A. \& Galluccio, G. Correlation between condylar size on CT and position of the articular disc on MRI of the temporomandibular joint. Cranio, 1-8, 2019. DOI: https://www.doi.org/10.1080/08869634.2019.1692283

Karssemakers, L. H. E.; Nolte, J. W.; Tuinzing, D. B.; Langenbach, G. E. J.; Becking, A. G. \& Raijmakers. P. G. Impact of bone volume upon condylar activity in patients with unilateral condylar hyperplasia. $J$. Oral Maxillofac. Surg., 76(10):2177-82, 2018.

Mostafavi, M.; Vahdat, A. S.; Javadian, L. \& Ghaznavi, A. Analysis of condylar volume in relation to craniofacial morphology using cone beam computed tomography. Contemp. Med. Sci., 4 4(4):202-6, 2018.

Nitzan, D. W.; Katsnelson, A.; Bermanis, I.; Brin, I. \& Casap, N. The clinical characteristics of condylar hyperplasia: experience with 61 patients. $J$. Oral Maxillofac. Surg., 66(2):312-8, 2008.

Nolte, J. W.; Verhoeven, T. J.; Schreurs, R.; Bergé, S. J.; Karssemakers, L. H. E.; Becking, A. G. \& Maal, T. J. J. 3-Dimensional CBCT analysis of mandibular asymmetry in unilateral condylar hyperplasia. $J$. Craniomaxillofac. Surg., 44(12):1970-6, 2016.

Nota, A.; Caruso, S.; Ehsani, S.; Baldini, A. \& Tecco, S. Three-dimensional volumetric analysis of mandibular condyle changes in growing subjects: A retrospective cross-sectional study. Cranio, 38(5):320-6, 2020.

Olate, S.; Netto, H. D.; Rodriguez-Chessa, J.; Alister, J. P.; de AlbergariaBarbosa, J. \& de Moraes, M. Mandible condylar hyperplasia: a review of diagnosis and treatment protocol. Int. J. Clin. Exp. Med., 6(9):72737, 2013.

Peck, C. C.; Goulet, J. P.; Lobbezoo, F.; Schiffman, E. L.; Alstergren, P.; Anderson, G.; de Leeuw, R.; Jensen, R.; Michelotti, A.; Ohrbach, R.; et al. Expanding the taxonomy of the diagnostic criteria for temporomandibular disorders. J. Oral Rehabil., 41(1):2-23, 2014.

Raijmakers, P. G.; Karssemakers, L. H. E. \& Tuinzing, D. B. Female predominance and effect of gender on unilateral condylar hyperplasia: a review and meta-analysis. J. Oral Maxillofac. Surg., 70(1):e72-6, 2012.

Saccucci, M.; D’Attilio, M.; Rodolfino, D.; Festa, F.; Polimeni, A. \& Tecco, S. Condylar volume and condylar area in class I, class II and class III young adult subjects. Head Face Med., 8:34, 2012.
Safi, A. F.; Kauke, M.; Grandoch, A.; Nickenig, H. J.; Zöller, J. E. \& Kreppel, M. Age-related volumetric changes in mandibular condyles. $J$. Craniofac. Surg., 29(2):510-3, 2018.

$\mathrm{S}_{s}$ allı, G. A. \& Öztürkmen, G. Semi-automated three-dimensional volumetric evaluation of mandibular condyles. Oral Radiol., 37(1):6673, 2021.

Saridin, C. P.; Raijmakers, P. G. H. M.; Tuinzing, D. B. \& Becking, A. G. Bone scintigraphy as a diagnostic method in unilateral hyperactivity of the mandibular condyles: a review and meta-analysis of the literature. Int. J. Oral Maxillofac. Surg., 40(1):11-7, 2011.

Shyu, V. B. H.; Hsu, C. E.; Chen, C. H. \& Chen, C. T. 3D-assisted quantitative assessment of orbital volume using an open-source software platform in a Taiwanese population. PLoS One, 10(3):e0119589, 2015.

Tecco, S.; Saccucci, M.; Nucera, R.; Polimeni, A.; Pagnoni, M.; Cordasco, G.; Festa, F. \& Iannetti, G. Condylar volume and surface in Caucasian young adult subjects. BMC Med. Imaging, 10:28, 2010.

Vellone, V.; Costantini, A. M; Ramieri, V.; Fegatelli, D. A.; Galluccio, G. \& Cascone, P. Unilateral condylar hyperplasia: a comparison with two open-source softwares. J. Craniofac. Surg., 31(2):475-9, 2020.

Verhoeven, T. J.; Nolte, J. W.; Maal, T. J. J.; Bergé, S. J. \& Becking, A. G. Unilateral condylar hyperplasia: a 3-dimensional quantification of asymmetry. PLoS One, 8(3):e59391, 2013.

Wallner, J.; Hochegger, K.; Chen, X.; Mischak, I.; Reinbacher, K.; Pau, M.; Zrnc, T.; Schwenzer-Zimmerer, K.; Zemann, W.; Schmalstieg, D.; et al. Clinical evaluation of semi-automatic open-source algorithmic software segmentation of the mandibular bone: Practical feasibility and assessment of a new course of action. PLoS One, 13(5):e0196378, 2018.

Xi, T.; van Loon, B.; Fudalej, P.; Bergé, S.; Swennen, G. \& Maal, T. Validation of a novel semi-automated method for three-dimensional surface rendering of condyles using cone beam computed tomography data. Int. J. Oral Maxillofac. Surg., 42(8):1023-9, 2013.

Corresponding author:

Prof. Adriana A. De Stefano

Universidad Central de Venezuela

Facultad de Odontología

Cátedra de Ortodoncia

Av. Los llustres

Ciudad Universitaria

Caracas

VENEZUELA

\section{E-mail: aadestefano@hotmail.com}

ID: https://orcid.org/0000-0001-5115-3582

Received: 10-03-2021

Accepted: 29-05-2021 